\title{
Experimental study and isolation mechanism analysis on emulsion wax curing agent used on cement-stabilized granular base
}

\author{
Jianbo Yuan ${ }^{1} \cdot$ Taoyu Zhang $^{2} \cdot$ Jialiang Yao ${ }^{2,3}$
}

Received: 13 May 2016/Accepted: 20 July 2016/Published online: 4 August 2016

(C) Springer International Publishing Switzerland 2016

\begin{abstract}
Based on the analysis in the mechanism of emulsion wax curing agent (EWCA) which was regarded as bond-breaking layer of concrete pavement, tests for shear stress, penetration test, pendulum friction coefficient test and sliding friction coefficient test are operated. Indexes for tests are measured after the spraying of EWCA on cement-stabilized granular base (CSGB). Compared with base do not have bond-breaking layer, test results indicated that bond stress, friction coefficients and permeability coefficients had been separately reduced by 64,62 and $9 \%$ with the help of EWCA. As a result it will improve the impermeability of CSGB. Pendulum friction coefficient test and sliding friction coefficient test are conducted, on cement-stabilized base's surface with different texture depth 3 days after the spraying of EWCA. According to variation of sliding friction coefficient and British Pendulum Number (BPN), it can be concluded that they will decrease as increasing of spraying dosage and tend to stable finally. Field interlayer tangential bond force test with EWCA being sprayed on lean concrete base (texture depth $<0.3$ ) is performed. The results indicates:
\end{abstract}

Taoyu Zhang

toryz@qq.com

Jianbo Yuan

yuanjb01@163.com

Jialiang Yao

yao26402@126.com

1 Chengnan College, Changsha University of Science and Technology, 410076 Hunan, Changsha, China

2 School of Traffic and Transportation Engineering, Changsha University of Science and Technology,

410114 Hunan, Changsha, China

3 Key Laboratory of Road Structure and Material of Ministry of Transport, 410114 Changsha, China spraying time has significant effect on jacking force; wearing after form the film and rainfall have less effect on jacking force. The experimental results indicate that longer the time interval (from spraying the EWCA to pouring the pavement), the worse the effect of isolation. As a conclusion of engineering, the construction of isolation layer should be finished a few days before the construction of pavement.

Keywords Waxed curing agent $\cdot$ Isolation layer $\cdot$ Cement concrete base $\cdot$ Friction permeability coefficient

\section{Introduction}

Cement-stabilized granular base (CSGB) not only provides desirable support and load transfer for the pavement surface slabs, but also offers a good working platform to construction machinery and formwork, as well as helps prevent pumping. Therefore, CSGB is applied more and more in the heavy traffic pavements. However, the existing findings of all experimental studies have shown that high friction frequently exists between CSGBs and the concrete pavement surface slabs [1]. A way to reduce the friction is to lay an intermediate layer between the CSGB and the surface slab, or a bond-breaking layer.

The main functions of bond-breaking layer include reducing the bonding of the surface slabs to the CSGB, reducing the frictional resistance between layers. The bond-breaking layer's role also conclude eliminating the weak transition layer between the concrete surface slab and the base resulted from the construction process, reducing the occurrence of the early broken slabs of cement concrete pavement [2,3] Alternatively, it can effectively prevent the base from damaging during the construction, improve the anti-erosion ability of the 


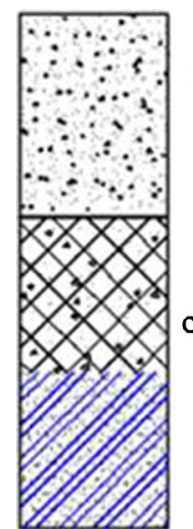

$28-32 \mathrm{~cm}$ cement concrete surface course

EWCA bond-breaking layer

$20-22 \mathrm{~cm}$ base course of cement treated crushed rocks

Soil subgrade

Fig. 1 Schematic of the pavement structure of Yun-Luo Highway

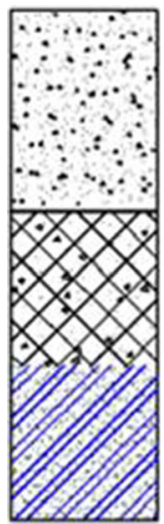

$26 \mathrm{~cm}$ cement concrete surface course

EWCA bond-breaking layer

$20 \mathrm{~cm}$ base course of cem ent treated crushed rocks

\section{Recycled original cement} pavement as subabse course

Fig. 2 Schematic of the pavement structure of the Province Road 358

cement-stabilized granular base [4], and even offer the vibration-buffering function [5].

The bond-breaking layers can be constructed in a variety of approaches [6]. Research in this paper, combined with the engineering projects including the construction of the Changsha-Shaoshan-Loudi Highway (in Hunan Province), the Yunfu-Luoding Highway (in Guangdong Province, the structure is shown in Fig. 1) and the rehabilitation of the Province Road 358 within Dongguan of Guangdong Province (the structure is shown in Fig. 2), carried out the experimental studies on the bond-breaking layers with various bonding-breaking media including emulsified asphalt slurry seal (EASS), geotextile and emulsion wax curing agent (EWCA). These studies systematically compared the different mechanical performance of the slabbase interface with different bond-breaking media. Firstly, the mechanism of the effect of wax on the cement pavement segregation layer and the effect of isolation effect on the cement stabilized base layer are analyzed. The findings derived from this research are expected to offer scientific reference to the option of bond-breaking approach and the quality control of construction of bond-breaking layers in the future similar engineering projects.
Analysis in the mechanism of emulsion wax curing agent (EWCA) which was regarded as bondbreaking layer of cement-stabilized granular base (CSGB)

The fundamental constituent of emulsion wax curing agent (EWCA)is an emulsion wax with a dispersed multiphase system. The commonly made emulsion wax is called oil-inwater emulsion wax, with tiny wax particles (less than $1.5 \mu \mathrm{m}$ in diameter) dispersed in the water. The basic components of emulsion wax include waxes, oil, polymers, emulsifiers, additives and water. Commonly used emulsifiers include cationic, anionic and non-ionic surfactant. Polymers include polyvinyl alcohol, three acrylic ester monomer, vinyl chloride and etc. The mechanism of emulsion wax curing agent which was regarded as bondbreaking layer of cement concrete pavement base listed as follows.

\section{Deducing the bonding of cement}

According to the bonding theory, there are two kinds of surface bonding: one is chemical bonding which is also named as Van Der Waals forces bonding, the other one is physical bonding which formed by physical bonding and whose strength is positively related to the roughness of surface. The main bonding is in the form of chemistry, so as the damage of the bonding. Because of the weak polarity, Van Der Waals forces and the bonding with high difficulty, the effect of bonding will seriously be damaged by the interference into surface of concrete. Even the bonding between concrete layer will be damaged by the wax membrane on a molecular level. As it can largely induce the bonding between the concrete of base and cement paste under cement pavement board, the EWCA bond-breaking layer will effectively cut down the degree of binding between the base and the pavement. As bondbreaking material, the EWCA's main function is to reduce the bond of concrete.

\section{Increasing the effect of lubrication and deducing the interlayer friction}

Without bond-breaking layer, there are high friction between the base and pavement for the bonding between the cement-stabilized base and cement pavement and the rugged surface of the base. The paraffin wax is a kind of lubricants. The fundamental constituent of emulsion wax curing agent (EWCA) is an emulsion wax with a dispersed multiphase system. So waxed membrane layer can provide effective lubrication between the base and the pavement [7], and it also can reduce the interlayer friction between 
the base and the pavement under the effect of loading and warping stresses. The other bond-breaking layer do not provide the feature of wax.

\section{Diminishing the development of the weak transition layer}

Paved between cement concrete pavement and base, the interface is a thin layer with complicated structure. Owing to the rough interfaces caused by the surface's pore or the roughness which was formed after the cement-stabilized base was constructed, it is the weakest interface and was called the transition region in the structure. Poured on such base, cement slurry penetrate into the pore of base with some depth, and the penetration depth was determined by the maximal particle size of base material, the porosity and the property of bondbreaking layer. Formed by penetrated cement slurry, exposed aggregates in the base and hardened cement pastes, the weak joint surface was easily damaged with vehicle load and environmental factors. The surface are different form the base and the pavement. Naturally, it will have impact on the stress condition and the reliability of the pavement $[2,8]$.

Formed by the EWCA on the surface of the hydrophilic base, the water-phobic membrane can permeate into the base surface through its pore and prevent cement slurry from permeating on condition that the pavement was paved. As a result, it will diminish the development of the weak transition layer on the course of cement pavement's bottom was constructed.

\section{Waterproofing of EWCA bond-breaking layer}

Paraffin wax can be used as waterproof material [9] for the production of the corrugated board, the fiberboard and the paper. Used as bond-breaking layer, EWCA can provide a function of waterproof and anti-erosion for the reason that tiny wax particles of EWCA can penetrate into the cementstabilized base with the help of penetrant, and hence block the pore of the cement-stabilized base in an effective way. In addition, membrane will be continuously formed on the surface of the cement-stabilized base under the effect of aerial oxidation and self-polymerization, which also contribute to prevent the water from evaporating and penetrating. In a result, the EWCA can be used for the curing after finishing the construction of the cement-stabilized base and improving whose property of waterproof and anti-erosion.

\section{Emulsion wax curing agent (EWCA)}

The choice of EWCA was primarily determined by its curing function and bond-breaking function, with consideration of relevant standards and literatures both at home
Table 1 Properties of EWCA as interlayer material

\begin{tabular}{ll}
\hline Property & Requirements \\
\hline $\begin{array}{l}\text { The effective water-retention } \\
\text { rate of } 3 \text { days } / \%\end{array}$ & $\geq 90$ \\
$\begin{array}{l}\text { The ratio of compressive } \\
\text { strength of concrete/\% }\end{array}$ & $\geq 95$ \\
The abrasion value of concrete/ & $\leq 3.0$ \\
$\quad\left(\mathrm{~kg} / \mathrm{m}^{2}\right)$ & \\
Solid content $/ \%$ & $\geq 25$ \\
$\begin{array}{l}\text { Drying time (h) } \\
\text { Soluble film after immersion in } \\
\text { water }\end{array}$ & $\leq 4$ \\
$\begin{array}{l}\text { Deposition heat resistance } \\
\text { Shelf life }\end{array}$ & Qualified \\
Viscosity ( $25{ }^{\circ} \mathrm{C}$, smear four & 6 months \\
cup viscosity) & $12-20$ \\
Effect of (hazardous) on & After the spray does not affect \\
concrete & the quality of concrete \\
\hline
\end{tabular}

and abroad, as well as requirements of the tests conducted in this research. Used for bond-breaking, its solid content was no less than $25 \%$, with the mass ratio of polymer materials to paraffin being 1:2 and a qualified film-forming property. Time of film formation refers to the required time from after spraying curing agent to splashed water forming oil bead on the surface, generally between 1 and $5 \mathrm{~h}$. The time of film formation can be used to determine the minimum interval between spraying curing agent and paving the surface slabs or the time without covering the plastic film after spraying before rain. For EASS with solid content no less than $25 \%$ and the mass ratio of polymer materials to paraffin being $1: 2$, the application rate for spraying was specified to be $0.4 \mathrm{~L} / \mathrm{m}^{2}$ and no less than $0.35 \mathrm{~L} / \mathrm{m}^{2}$ as the minimal. The special machine was used to spray so as to ensure uniformity of spraying and to control the application rate for spraying.

EWCA is mainly chosen by the function requirements of maintenance and isolation, home and abroad research and tests in this paper. EWCA is a kind of white aqueous emulsion with properties of non-toxic, incombustible, noncorrosion and a good level of security. Product performance and technical indicators should comply with the provisions of the Table 1, and the inspection standard is operated by national standard [13], ASTM [10] and AASHTO [11].

\section{Experimental study}

\section{Tests for bond stress at slab-base interface of pavements with EWCA bond-breaking layers}

The interface between the cement concrete surface slab and the CSGB is a weak link in this kind of pavements, also 

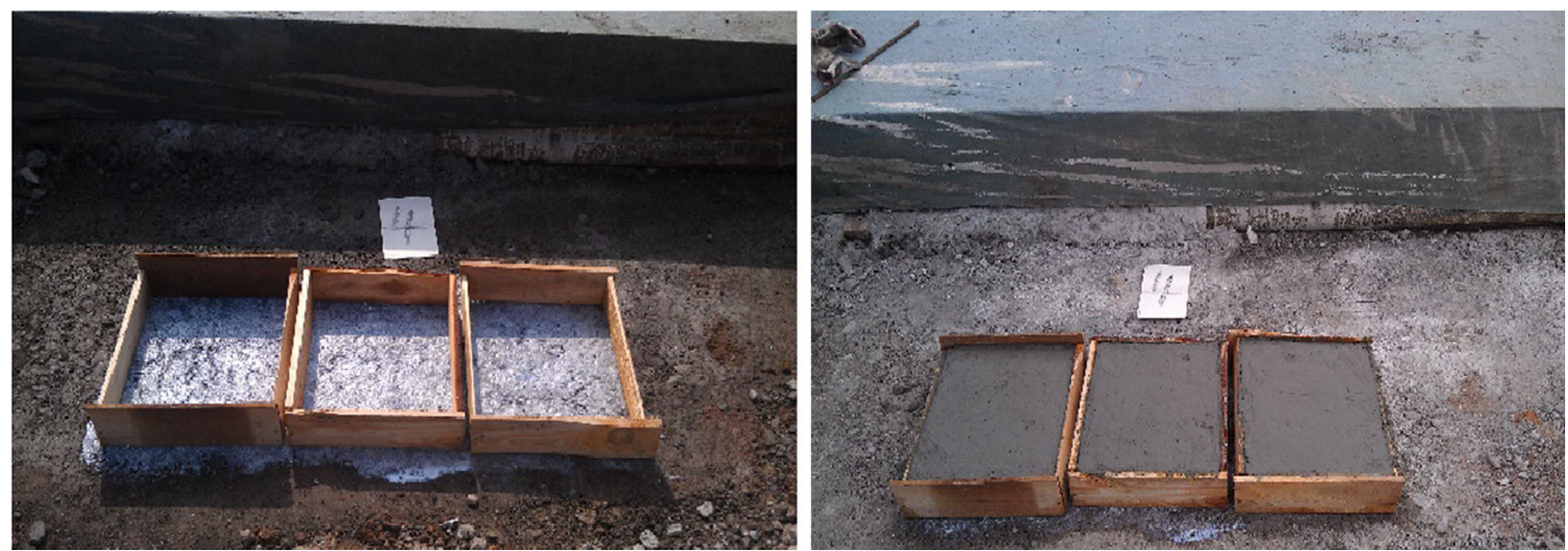

Fig. 3 Specimen for interlayer shear bond stress

known as the transition layer. The interface shear and bond strength of the transition layer are weaker than the concrete strength of its both adjacent layers. Therefore, the transition layer is prone to be damaged under effect of vehicle load and some environmental factors, which affects the stress state and reliability of the surface slabs. The performance of transition layer is determined by construction of the surface slabs, concrete performance and type of the bond-breaking layer. And performance of the transition layer can be analyzed via the microstructure and the tests of macroscopic mechanical properties.

Currently, still in the dark are the strength formation mechanism of the slab-base interface and its mechanical behavior before and after failure. Thus, it is necessary in the engineering projects to carry out analysis and tests on the interlayer mechanical properties, with consideration of the field conditions. Such analysis and tests not only contribute to understanding essentially the relationship between material microstructure and its macroscopic mechanical behavior, and also prove the model of slab-base contact via the research on mechanical properties of the slab-base interface (in terms of the slab-base bonding, cement pavements can be divided into unbonded, bonded and partially-bonded pavements), so as to optimize the bond-breaking approach and establish the on-site construction quality control standards and methods for bondbreaking layers.

To prove the EWCA mechanism and to analyze the weak slab-base interface layer, it is necessary to understand the situation of the slab-base bonding. In the engineering projects appropriate measures must be taken to control the slab-base bonding to prevent the cracking of the concrete pavement during construction. The slab-base bond includes shear bond and pull-out bond, but is mainly shear bonding. Considering all of these, combined with engineering projects, the research in this paper performed the tests for slabbase shear bond stress. At present, there is no standard for the evaluation of the effect of isolation layer on cement pavement, and the method is high in cost and difficulty in literature [7]. In this paper, based on the above research, the main mechanism of the isolation layer based on EWCA: reduce friction and reduce the bonding between layers, and develop the field layer shear test which is used to evaluate the effect of isolation.

To analyze the slab-base shear bond stress, the field tests for the slab-base shear bond stress and composite friction coefficient were conducted in the research of this paper to compare bond-breaking conditions between the cement concrete surface slabs and the CSGB (its surface texture depth $<0.45$, the local is not more than $0.6 \mathrm{~mm}$.). These bond-breaking types included (1) emulsion wax curing agent (EWCA) as bond-breaking layer (BBL) and (2) without any bond-breaking layer.

In this research, the field tests for the slab-base shear bond stress and composite friction coefficient were performed with an imposing horizontal thrust force to the end of rectangular specimens C35 till these specimens failed. The maximum horizontal thrust right before the failures were recorded. Specimens C35 with a size of $350 \mathrm{~mm} \times 350 \mathrm{~mm} \times 80 \mathrm{~mm}$ and a dead weight of 21-24 kg were molded atop the CSGB surfaces (as shown in Fig. 3) treated with different bond-breaking types as discussed above. Only after the specimens reached compression strength of 30-35 MPa were the tests conducted. These tests were expected to simulate the fact the shear bond stress or friction possibly occurred when the cement concrete surface slab was constrained in the deformation process. Figure 4 presents the test for shear bond stress conducted on the CSGB top treated with EWCA as the bond-breaking layer. The loaded trucks are used in the tests to offer reaction forces. Center of the lifting hydraulic jack, center of the force-measuring gauge and center of the specimens were located at the same horizontal level and in a line. For loading, the lifting hydraulic jack applied the 


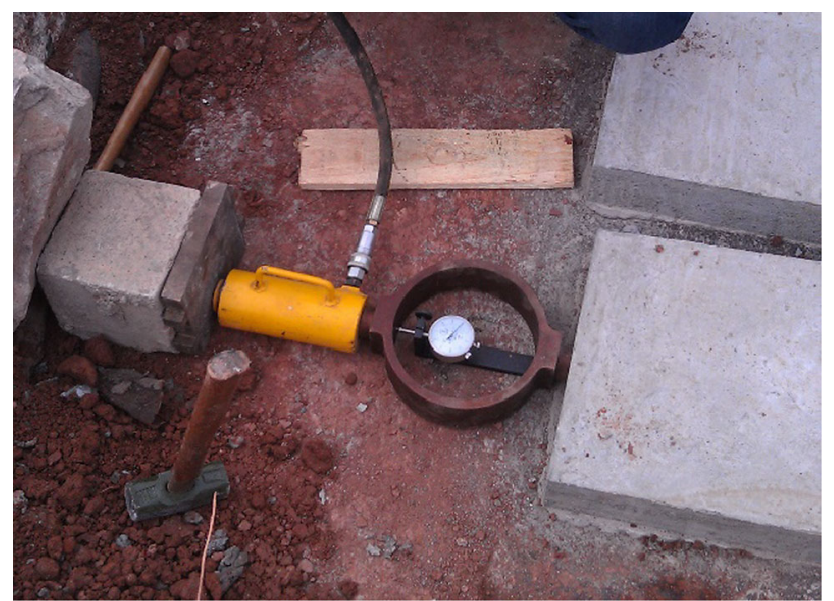

Fig. 4 Tests for interlayer shear bond stress and composite friction coefficient

horizontal thrust forces slowly until the specimens fully broke from the base top. The maximum value showed on the force-measuring gauge at this time was recorded and served as the max horizontal thrust. The maximum slabbase shear stress was determined by the ratio of the maximum horizontal thrust $T_{\max }$ to the shear area $A\left(350 \times 350 \mathrm{~mm}^{2}\right)$,

$\tau=T_{\max } / A$.

Composite friction coefficient $f_{\mathrm{h}}$ was the ratio of the maximum horizontal thrust of specimen $T_{\max }$ to the dead weight of specimen $m$ [9],
$f_{\mathrm{h}}=T_{\max } / m$.

The computed results were given in Tables 2 and 3. The test results (see Table 2) showed the shear bond stress was reduced by approximately $64 \%$ in the case of EWCA as the bond-breaking layer, which shows the composite friction coefficient decreased by $62 \%$ in the case of as the bond-breaking layer. The slab-base shear stress (shear bond stress) varied in the same pattern with the composite friction coefficient.

\section{Pendulum friction coefficient test}

To measure the slide-ability of pavement's surface (spraying with EWCA), this paper evaluates British Pendulum Number (BPN) by portable pendulum tester which was often used in reality. BPN is the abbreviation of British Pendulum Number, and it is values of portable pendulum tester. For the reason that the strong thermo-sensitivity of portable pendulum tester's rubbery slider, it is required to correct the BPNt with $\triangle \mathrm{BPN}$. The conversion formula is listed as Formula (3),

$\mathrm{BPN} 20=\mathrm{BPNt}+\triangle \mathrm{BPN}$,

where: BPN20 - converted value of BPN when temperature of pavement is $20^{\circ} \mathrm{C}$; $\mathrm{BPNt}$-measured value of BPN when temperature of pavement is $T^{\circ} \mathrm{C} ; \Delta \mathrm{BPN}$ - correction value of temperature.

Table 2 Result of interfacial shear stress tests

\begin{tabular}{llllll}
\hline $\begin{array}{l}\text { Type of bond-breaking } \\
\text { layer (BBL) }\end{array}$ & $\begin{array}{l}\text { Horizontal } \\
\text { thrust }(\mathrm{kN})\end{array}$ & $\begin{array}{l}\text { Test piece bottom } \\
\text { area }\left(\mathrm{cm}^{2}\right)\end{array}$ & $\begin{array}{l}\text { Bond stress } \\
(\mathrm{MPa})\end{array}$ & $\begin{array}{l}\text { Average bond } \\
\text { stress }(\mathrm{MPa})\end{array}$ & $\begin{array}{l}\text { Bond stress } \\
\text { reduction rate }(\%)\end{array}$ \\
\hline No BBL & 37.5 & 1163.5 & 0.32 & 0.31 & Reference \\
& 35 & 1128 & 0.31 & & \\
EWCA & 36.25 & 1199.3 & 0.30 & 0.11 & 64 \\
& 12.5 & 1266.5 & 0.12 & \\
\hline
\end{tabular}

Table 3 Result of interfacial composite friction coefficient tests

\begin{tabular}{llllll}
\hline $\begin{array}{l}\text { Type of bond-breaking } \\
\text { layer (BBL) }\end{array}$ & $\begin{array}{l}\text { Horizontal } \\
\text { thrust }(\mathrm{kN})\end{array}$ & $\begin{array}{l}\text { Test piece } \\
\text { weight }(\mathrm{kN})\end{array}$ & $\begin{array}{l}\text { Composite friction } \\
\text { coefficient }\end{array}$ & $\begin{array}{l}\text { Average composite } \\
\text { friction coefficient }\end{array}$ & $\begin{array}{l}\text { Composite friction coefficient } \\
\text { reduction rate }(\%)\end{array}$ \\
\hline No BBL & 37.5 & 0.22736 & 165 & 153 & Reference \\
& 35 & 0.24108 & 145 & & 62 \\
EWCA & 36.25 & 0.24402 & 149 & 58 & \\
& 12.5 & 0.2254 & 55 & & \\
& 13.75 & 0.2156 & 64 & & \\
\hline
\end{tabular}




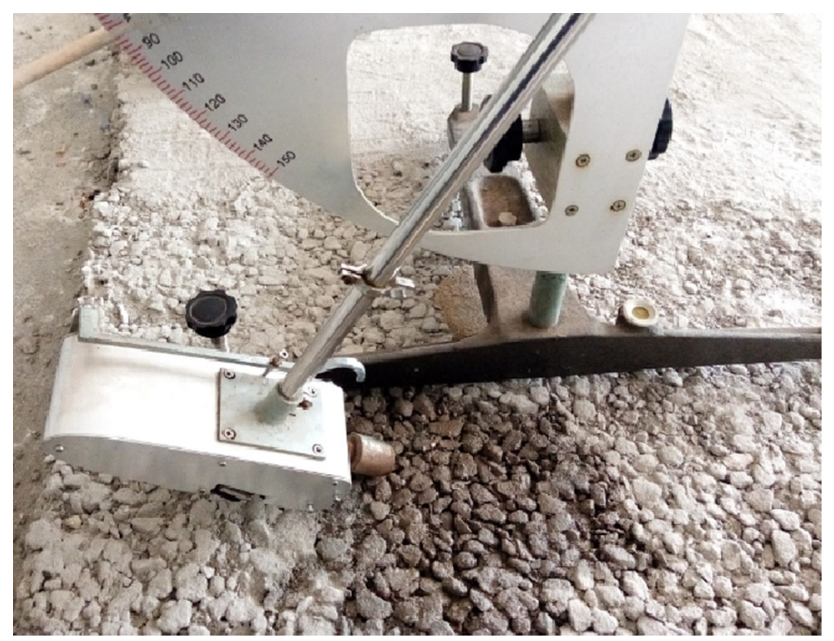

Fig. 5 Pendulum friction coefficient test on cement-stabilized base

The test is performed on the surface of pavement whose averaged texture depth is $0.31,0.61$ and $1.38 \mathrm{~mm}$ and it realized by cutting machine and adjusting the mixture of base (Fig. 5). EWCA will be sprayed on the condition that cement-stabilized base has enough strength. Pendulum friction coefficient test will be conducted 3 days after the spraying of EWCA. The results appear in Fig. 6.

Conclusion from the results appeared in Fig. 6:

1. As the spraying of EWCA on cement-stabilized base's surface with different texture depth, BPN significantly decreased.

2. Compared with not spraying EWCA, the BPN of cement-stabilized base's surface will decrease the most when the dose of spraying is $0.2 \mathrm{~L} / \mathrm{m}^{2}$. According to the dose, EWCA is sprayed on the cement-stabilized base's surface with texture depth of 1.38, 0.61 and $0.31 \mathrm{~mm}$. The decreasing degrees were 30,35 and $36 \%$, and they will be slow as the increasing of spraying dose. In contrast, BPN will decrease if the dose of spraying is $0.4 \mathrm{~L} / \mathrm{m}^{2}$, and the decreasing degrees were $7.4,10.2$ and $14.6 \%$.

3. According to variation of BPN, it can be concluded that BPN will decrease as increasing dose of spraying. The decreasing degree of BPN will decrease to 0 . Finally, BPN will tend to stable.

\section{Sliding friction force (measuring the jacking force after the bind is lost) test}

To clearly reflect the relation of normal pressure and horizontal jacking forces, the coefficient of friction is cited. It represents the difficulty of beam's being pushed. In addition, the sliding difficulty of pavement deformation can be simulated. The sliding friction coefficient " $f$ " is defined as the ratio of horizontal jacking force " $F$ " to beam's own weight " $M$ ", and it is a dimensionless value. The formula is performed as Eq. (4), indoor test is listed in Fig. 7 and, results of sliding friction coefficient test is listed in Fig. 8, $f=F / M$.

It can be indicated from the results of Fig. 8,

1. EWCA is sprayed on cement-stabilized base's surface with different texture depth, jacking force and sliding friction coefficient significantly decreased.

2. Horizontal jacking forces significantly decreased if EWCA is sprayed on the cement-stabilized base's surface. Compared with not spraying EWCA, the cement-stabilized base's surface with different texture depth's horizontal jacking forces will decrease the most when the dose of spraying is $0.2 \mathrm{~L} / \mathrm{m}^{2}$. The decreasing degrees of horizontal jacking forces and sliding friction coefficient will be slow as the increasing of spraying dose.

3. According to variation of sliding friction coefficient, it can be concluded that sliding friction coefficient will decrease as increasing dose of spraying. The
Fig. 6 Results of friction coefficient test on cementstabilized base's surface with different texture depth

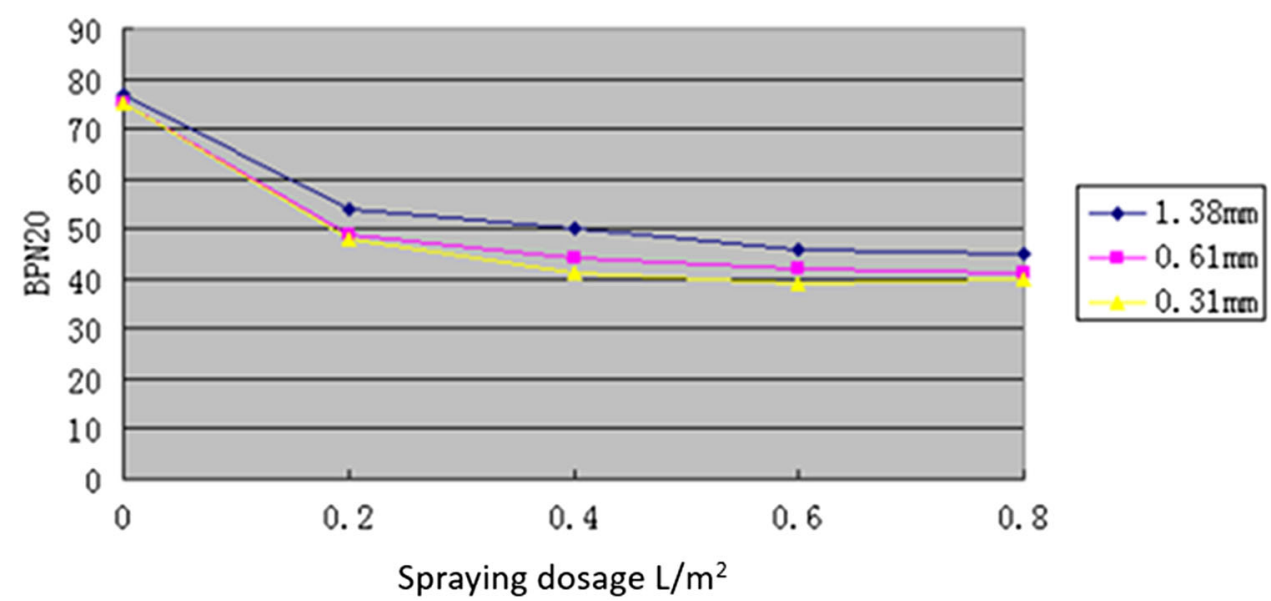




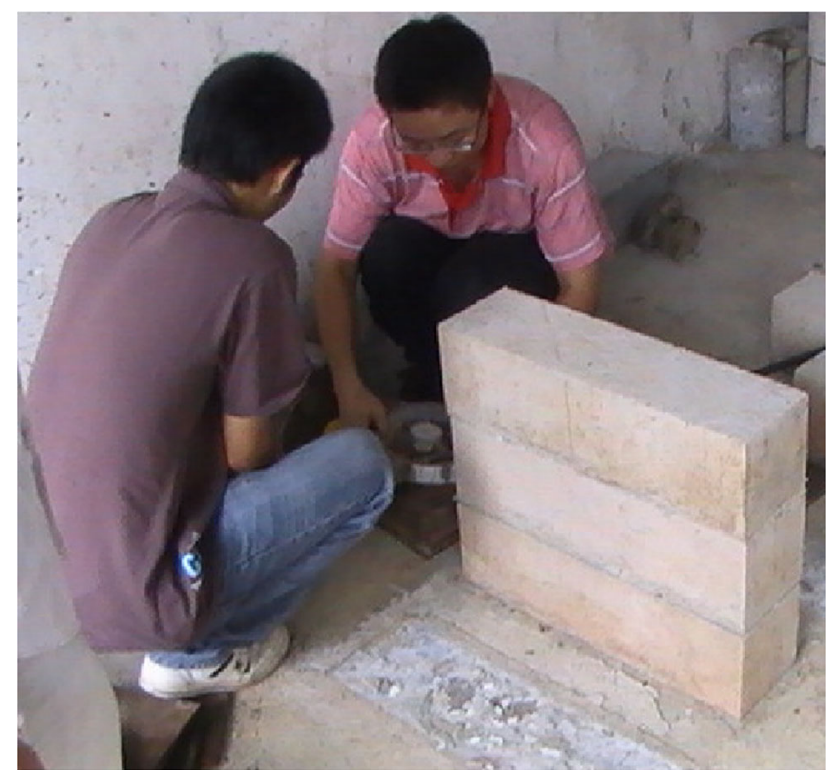

Fig. 7 Sliding friction coefficient test with stacked beams being pushed

decreasing degree of sliding friction coefficient will decrease to 0 . Finally, sliding friction coefficient with different texture depth will tend to stable.

\section{Penetration test}

The improvement of the anti-permeability of CSGB by the bond-breaking layer material can be evaluated by the water seepage experiment. Water seepage experiment is the experimental study of the permeability of water, which is the vertical direction of the material. The seepage coefficient [12] refers to the volume of water that is required to penetrate into the surface of the pavement under the condition of the initial head pressure, to $\mathrm{mL} / \mathrm{min}$.

The instrument used in the experiment is the HDSS-II type of the pavement, and the instrument is shown in
Fig. 8. In the experiment, the choice of the flat surface of the test, the instrument and the cement stabilized base between the good seal, after the instrument into the water (preferably a color of water, so easy to distinguish). Open the instrument, record the liquid surface from time to time to start the end of the flow of water volume, attention to the beginning of the first injection of about $50 \mathrm{~mL}$ of water (different instruments slightly different) and then experiment. If the water penetration time is too long, then calculate using 3 min down the amount of water (Fig. 9).

The seepage coefficient could compute via Eq. (5). Results of this test were given in Table 4 ,

$C_{\mathrm{W}}=\left(V_{2}-V_{1}\right) \div\left[\left(t_{2}-t_{1}\right) \times 60\right]$,

where $C_{\mathrm{W}}$ seepage coefficient $(\mathrm{mL} / \mathrm{min}) ; \mathrm{V}_{1}=$ the scale for the start of the time $(\mathrm{mL}) ; \mathrm{V}_{2}=$ the scale of the cylinder at the end of the time $(\mathrm{mL}) ; t_{1}=$ time for the start time (s); $t_{2}=$ time for the end of time (s).

The seepage test is practically verified that the vertical drainage condition of water flow on the top of the top surface of the CSGB in the case of the non-bond-breaking layer and bond-breaking layer of the EWCA. The vertical drainage of the top of the base will have an important influence on the accumulation of water in the top of the base. For example, if the water easily enters through the basic level to enter the basic level, the base's water content will increase and its state will turn to wet state from dry state. When the water content is too large, under the action of the dynamic load, the CSGB may cause erosion damage.

\section{Construction and application study of EWCA being sprayed as isolation layer on the lean concrete base}

To obtain a program and construction experience, this paper develops the study based on project entity. Interlayer horizontal jacking force test will provide evidence for
Fig. 8 Results of sliding friction coefficient test on cement-stabilized base's surface with different texture depth

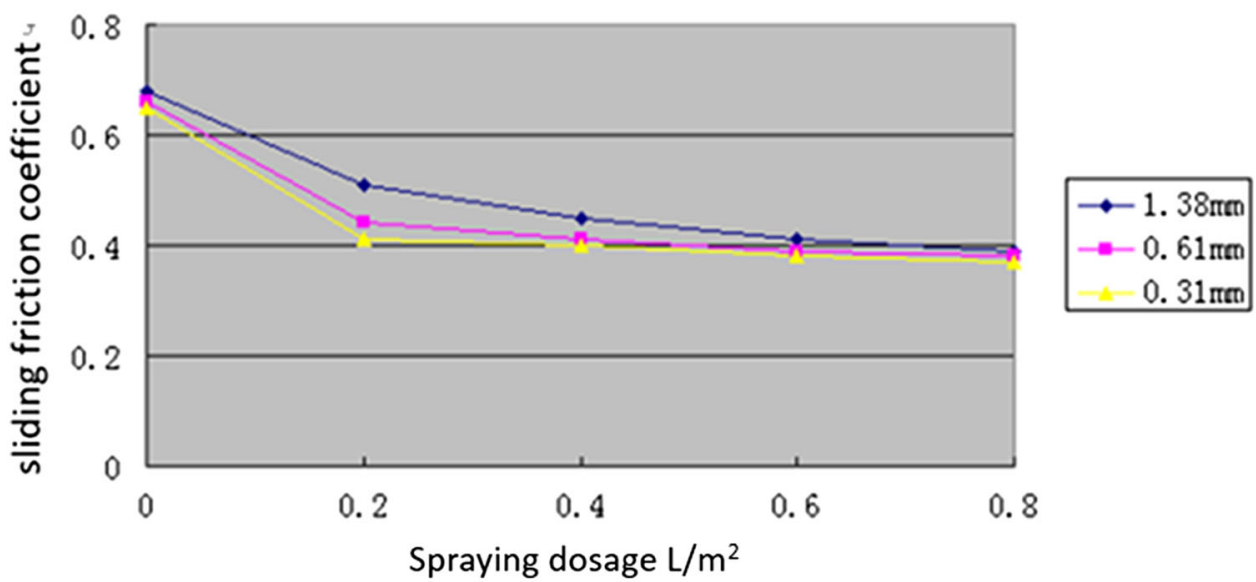




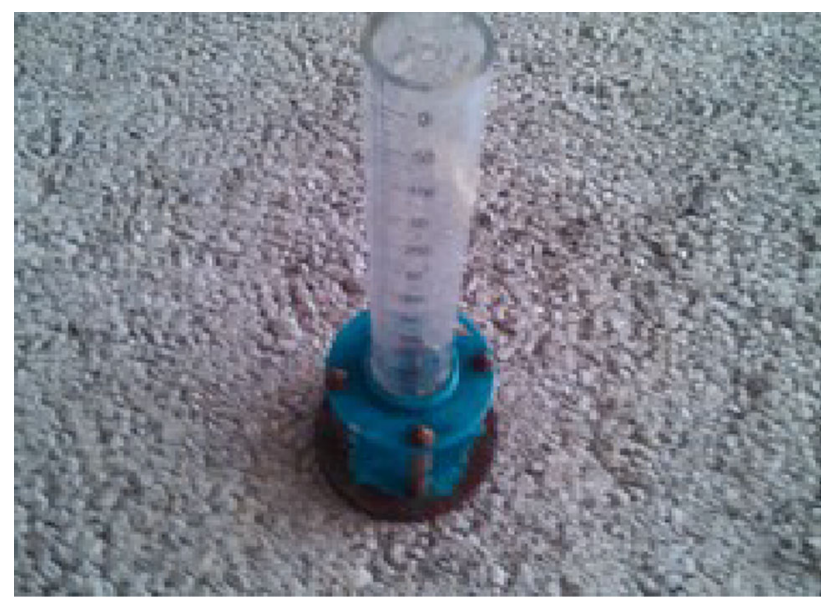

Fig. 9 HDSS-II type water seepage experimental apparatus

Table 4 Results of seepage experiment

\begin{tabular}{llll}
\hline $\begin{array}{l}\text { Type of bond- } \\
\text { breaking layer } \\
(\mathrm{BBL})\end{array}$ & $\begin{array}{l}3 \text { min seepage } \\
\text { quantity }(\mathrm{mL})\end{array}$ & $\begin{array}{l}\text { Seepage } \\
\text { coefficient } \\
(\mathrm{mL} / \mathrm{min})\end{array}$ & $\begin{array}{l}\text { Seepage } \\
\text { coefficient } \\
\text { reduction } \\
\text { rate }(\%)\end{array}$ \\
\hline No BBL & 71.6 & 23.8 & $\begin{array}{l}\text { Reference } \\
\text { EWCA }\end{array}$ \\
\hline
\end{tabular}

design and construction control of cement pavement project.

Author's main test on interlayer mechanical properties is field interlayer tangential bond force test with EWCA being sprayed on lean concrete base (texture depth $<0.3$ ). Results and experimental content are listed as follows:

\section{Effect of vehicles, rainfall and spraying time}

Effect of isolation will be mainly impacted by vehicles, rainfall and dust in the process of construction. For this problem, related tests are operated in process of field test and trial road paving. For example, grind the surface of base by plant after spraying EWCA on it, and then cement is poured on it for simulating the effect of construction vehicles' load; spraying time is defined from spraying EWCA on the jointed objects; isolation effect test is manipulated on the project which experienced rainfall after forming the film. The result can be seen in Tables 5 and 6 .

The results indicate: spraying time has a significant effect on jacking force; wearing after form the film and rainfall have less effect on jacking force. So, the construction of isolation layer should be finished a few days before the construction of pavement.

\section{The effect of pollution}

Because the pollution of large amount of dust in carriageway, EWCA film will turn from green-gray to light yellow or black after being sprayed for 3 days. The sample will be poured on the third day, and the interface shear test will be constructed for measuring the jacking forces after a week. The result is listed in Table 7 and it indicates that the effect of temporary pollution is not significant.

Table 5 Results of abrasion tests

\begin{tabular}{|c|c|c|c|c|}
\hline Types of isolation layer & $\begin{array}{l}\text { Jacking forces } \\
\mathrm{P} / \mathrm{kN}\end{array}$ & $\begin{array}{l}\text { Bond } \\
\text { stress/MPa }\end{array}$ & $\begin{array}{l}\text { Reduction rate } \\
\text { of bond stress/\% }\end{array}$ & $\begin{array}{l}\text { Coefficient of } \\
\text { variation/\% }(n=4)\end{array}$ \\
\hline The rolled and sliding base with no EWCA & $>25$ & $>0.30$ & Reference & - \\
\hline The rolled base with EWCA A & 6.02 & 0.07 & 76 & 13 \\
\hline The rolled base with EWCA A (wear) & 10.04 & 0.12 & 60 & 13 \\
\hline The sliding base with no EWCA A & 8.89 & 0.11 & 63 & 4 \\
\hline The sliding Base with no EWCA A (wear) & 14.26 & 0.17 & 43 & 6 \\
\hline
\end{tabular}

Ps wear means rubbing against surface of the base by stone plate, and then it will be poured with concrete specimen

Table 6 The effect of spraying time on thrust force

\begin{tabular}{|c|c|c|c|c|}
\hline Types of isolation layer & $\begin{array}{l}\text { Jacking forces } \\
\mathrm{P} / \mathrm{kN}\end{array}$ & $\begin{array}{l}\text { Bond } \\
\text { stress/MPa }\end{array}$ & $\begin{array}{l}\text { Reduction rate } \\
\text { of bond stress } / \%\end{array}$ & $\begin{array}{l}\text { Coefficient of } \\
\text { variation/\% }(n=4)\end{array}$ \\
\hline The rolled base with no EWCA & $>25$ & $>0.30$ & Reference & - \\
\hline Spraying EWCA, pouring concrete after 1 month & 8.58 & 0.11 & 63 & 13 \\
\hline $\begin{array}{l}\text { Spraying EWCA, rainfall after form the film, } \\
\text { pouring concrete after } 3 \text { days }\end{array}$ & 3.54 & 0.04 & 87 & 27 \\
\hline Spraying EWCA, pouring concrete after $10 \mathrm{~min}$ & 5.16 & 0.07 & 77 & 23 \\
\hline
\end{tabular}


Table 7 The effect of pollution

\begin{tabular}{llllll}
\hline Types of test & Types of isolation layer & $\begin{array}{l}\text { Jacking forces } \\
\mathrm{P} / \mathrm{kN}\end{array}$ & $\begin{array}{l}\text { Bond } \\
\text { stress/MPa }\end{array}$ & $\begin{array}{l}\text { Reduction rate } \\
\text { of stress/\% }\end{array}$ & $\begin{array}{l}\text { Coefficient of } \\
\text { variation/\% }(n=4)\end{array}$ \\
\hline \multirow{2}{*}{ Shear test } & The rolled base with no EWCA & $>25$ & $>0.30$ & Reference & - \\
& Spraying EWCA, pouring with pollution after 3 days & 3.54 & 0.04 & 85 & 27 \\
& Spraying EWCA, pouring with no pollution after 3 days & 6.23 & 0.07 & 76 & 10 \\
\hline
\end{tabular}

\section{Conclusion}

In this paper, we can draw the following conclusions by analyzing the mechanism and the experimental study of the EWCA for bond-breaking layer of the CSGB:

1. The EWCA on the CSGB for the cement concrete pavement segregation mechanism mainly includes: to reduce the cement bonding effect, to reduce the friction between the layers and waterproof barrier function.

2. Spraying curing compound BBL after layer between the bond stress is no BBL reduced rate of $64 \%$, comprehensive coefficient is no BBL reduced rate of $62 \%$.

3. Compared to the non BBL, the seepage coefficient of the BBL was reduced by $9 \%$.

4. The experimental results indicates: the longer the time interval (from spraying the EWCA to pouring the pavement), the worse the effect of isolation. Spraying time has significant effect on jacking force; wearing after form the film, rainfall and temporary pollution have less effect on jacking force.

Acknowledgments This research was supported by the National Natural Science Foundation of China under Grants 51578080, 51178064, 51302020 and the Transportation Department of Hunan Province, No. 201301.

\section{References}

1. Voigt GV (2008) Early cracking of concrete pavement-causes and repairs $[\mathrm{DB} / \mathrm{OL}]$. American Concrete Pavement Association,
2002-05-02. http://www.airtech.tc.faa.gov/naptf/att07/2002\% 20TRACK\%20P.pdf/P-68.pdf. Accessed May 2008

2. Yi Z, Tang B, Yang Q (2003) New structures of cement concrete pavements with bond breaker mediums. In: The corpus from the 1 st national forum of highway scientific and technical innovation. China Communications Press, Beijing, pp 84-88

3. Hu X (2010) Effects of transition layer on cement concrete pavement slab structure. J Changan Univ (Nat Sci Ed) 30(3):37-40

4. Li L (2006) Application of asphalt seal coating into cement concrete pavement structure. In: Collected papers of the 3rd session of Lu-Yue Highway and Bridge Equipment Forum. China Highway and Transportation Society, Beijing, pp 53-56

5. Kim J, Buttlar WG (2002) Analysis of reflective crack control system involving reinforcing grid over base-isolating interlayer mixture. J Transp Eng 128(4):375-384

6. Yao J, Yuan J, Zhang Q et al (2009) Research on mechanism of using emulsion wax curing agent as separation layer and its effectiveness. China J Highw Transp 22(6):47-52

7. Zhang H, Zhou Z, Chen X (2005) Research on the interfacial characteristics between PCC surface layer and poor cement concrete base course. J Changsha Commun Univ 21(4):27-31

8. Yi Z, Wu G, Zhou Z et al (2001) Failure process analysis of cement concrete pavement based on fracture mechanics and a new idea of pavement design. J Chongqing Jiaotong Univ 20(1): $1-4$ (in Chinese)

9. Gu J et al (1991) Study on the manufacturing technology of paraffin emulsion[J]. J Northeast For Univ 19(5):61-65

10. ASTM C309-03 Standard specification for liquid membraneforming compounds for curing concrete

11. AASHTO M148-05-UL Liquid membrane-forming compounds for curing concrete

12. Dai X (2009) Discussion of base course stress checking necessity in the design of cement concrete pavement. J Highw Transp Res Dev 26(2):22-26

13. Field test methods of subgrade and pavement for highway engineering (JTG E60-2008) 